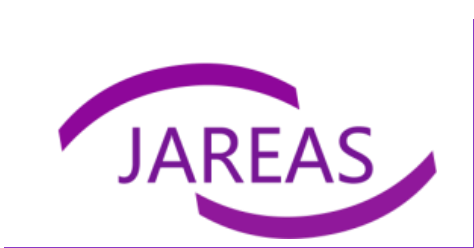

\title{
PERCEPTION LEVEL OF SMALL-MEDIUM ENTERPRISES EMPLOYEES AND THEIR ENVIRONMENTAL CORPORATE SOCIAL RESPONSIBILITY PRACTICES
}

\author{
Arunmozhi $M$ (D) Sumandiran C.S.P iD \\ ${ }^{1}$ Faculty, Bharathiar School of Management and Entrepreneur Development, Bharathiar University, Coimbatore, \\ India. \\ ${ }^{2}$ Founder and Director, Coimbatore Research Forum, Coimbatore, India.
}

\section{ARTICLE INFO}

Received: 10 October 2021

Revised: 12 November 2021

Accepted: 12 November 2021

Keywords:

Corporate Social Responsibility,

Perception Level,

Environmental CSR Activities.

Corresponding Author:

Arunmozhi M

Email:

m.arunmozhi81@gmail.com

Copyright () 2021 by author(s) and Journal of Advanced Research in Economics and Administrative Sciences.

This work is licensed under the Creative Commons Attribution International License (CC BY 4.0). http://creativecommons.org/licenses/ by/4.0/
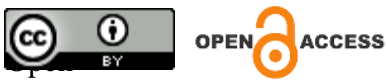

\begin{abstract}
Purpose: The current study examines the perception level of environmentaloriented CSR practices among the employees of small-medium enterprises in the Coimbatore district of Tamil Nadu, India.

Approach/Methodology/Design: It is a cross-sectional field study of environment CSR practices among SMEs employees of Coimbatore district, the western part of Tamil Nadu, India. A multistage random sampling technique is adopted. Sixty-one firms were approached to study the employees' perception of CSR and environmental impact on CSR. The sample included 369 participants out of the total population of 9027 employees. This study follows the research methodology based on the Eco-labeling principles, designed by the European Commission 2005 Descriptive analysis, Chi-square test, Bartlett sphericity statistical tests, and Structural Equation Modeling in AMOS version 23 were used..

Findings: The results indicate the significance of SMEs employees' perception level according to their age, gender and experience. The results reveal that CSR practices towards environments are related to employee perception level. CSR practices play a very predominant role in changing the mindset of the employees working in small-medium enterprises.

Practical Implications: This study also paves a way to diverse thoughts in the exploration of the multimodal dimensions of the internal aspects and external CSR practices.

Originality/value: The analysis presents the main directions of pro-environmental initiatives undertaken by enterprises and the perception of employees to understand environmental CSR. The results also indicate the differences in the most frequent pro-environmental activities of enterprises operating in the Coimbatore district of Tamil Nadu, India.
\end{abstract}

\section{INTRODUCTION}

Enterprises are progressively contributing to the ongoing deterioration of existing ecosystems by releasing massive amounts of harmful chemicals and making inappropriate use of available natural resources, posing a major threat to the biodiversity of our planet (Zelazna et al., 2020). As a result, a variety of actions must be implemented to halt the destruction of the environment caused by human activities. Initiatives targeted only at the neutralization of pollutants generated 
are no longer sufficient. It is important to look for ways to decrease the environmental impact of company activities at all stages of the manufacturing process, from the design stage and production planning to the manufacturing stage (Garetti \& Taisch, 2012). The main event that impacted the awareness of the importance of corporate social responsibility (CSR) was the European Commission's 2004 paper "Green Paper on CSR". According to this paper, social responsibility is an important component of management in European businesses, as well as an everyday practice for owners and managers. However, such an approach necessitates a significant shift in the way businesses are operated, as well as new managerial abilities, competencies, and mindset shifts among both management and employees(Jenkins, 2006; Argandoña\& Hoivik, 2009; Fenwick, 2010)

The evolution of the notion of corporate social responsibility in management theory reveals the changing aspects of the relationship between a company and society over time (Agudelo, et al., 2019). These distinctions govern how entities interact and collaborate. The previous two decades have seen an increase in the importance and prevalence of CSR activities, which may be ascribed to the obvious economic, social, and environmental advantages that have resulted. Corporate social responsibility, defined as voluntarily respecting social and environmental elements of company operations and relationships with stakeholders, has become a widely accepted concept on the Asian continent(Camilleri, M.A. 2017).

Corporate Social Responsibility (CSR) towards the natural environment is a business concept in which firms, in full conformity with the law and while still earning profits, voluntarily consider the environmental consequences of their operations in their business choices (Zelazna et al,. 2020). Such an approach helps to improve the quality of life while also putting the notion of sustainable development into practice. Socially responsible entities accept responsibility for the environmental consequences of their operations, work to reduce pollution and hazardous material emissions, and aim to improve the efficiency with which natural resources are used, thus, alleviating their ecological footprints.

It is important to remember that rapid economic expansion along with intensive exploitation of natural resources is in direct opposition to the need to conserve these resources for future generations. In reality, any nation can exploit existing resources to benefit its people; yet, governments must also conserve and preserve these resources for future generations. A survey of the literature on corporate social responsibility reveals that the majority of studies conducted thus far have focused on entire firms and their effects on various categories of stakeholders. Social responsibility was evaluated from the perspective of profitability for organizations that engage in socially responsible activities.

Glavas (2016) identifies three major themes in the discussion over corporate social responsibility. The first is on the role of businesses in society. The key question, which is frequently posed by default, is whether corporations have a role in society other than earning profit. The second tendency in the argument is whether corporate social responsibility is normative, which implies that corporations have an obligation to participate in socially responsible endeavors, or instrumental, which indicates that participation in CSR initiatives is in the best interests of the organization. Companies have a moral duty to society to care for their well-being if CSR is normative. The third tendency in the discussion is concerned with the effects of CSR on a company's financial performance. Proving that the firm's engagement 
in CSR may create more profit renders other motives (normative or instrumental) unnecessary, as CSR is about doing good for both the company and society. CSR, according to the World Business Council for Sustainable Development, is critical to long-term economic development and societal well-being.

This is why in-depth research on the profitability of socially responsible operations toward the silent stakeholder, the environment, is required. Eco-management aims to reduce the harmful effects that enterprises have on the environment. Growing societal awareness is putting pressure on corporations to lessen their environmental impact. The relationships between ecological and economic aims compete in the short run. However, as some writers suggest, environmental conservation may help a company's financial status by decreasing the costs of energy, raw materials, and so on.

This research contributes to the literature in several ways. First, we investigate the perception of CSR by employees in a developing country context and its potential impact on environment with a unique data set that includes survey data from 369 SME employees. Second, we corroborate previous findings on positive relationships between employees' environmental CSR perceptions in the current scenario (Gharleghi et al., 2018). Third, to the best of our knowledge, this is the first study to examine the association between CSR perception of employees and their perception of environmental attributes. Fourth, beyond examining direct effects, our study will contribute to the existing literature by exploring the underlying mechanism through which employees' general CSR perceptions are linked to Environmental CSR perceptions. Guided by a social learning perspective (Bandura, 1971), according to which an individual's attitudes and behaviors are modified as the person observes and attends to stimuli in the social environment, we propose that general perceptions of CSR activities are related to perceived CSR perception on environmental attributes. From a practical point of view, providing evidence of positive associations between employee perceptions of CSR and their environmental practices can foster the emergence of a clearer and stronger business case for CSR in SMEs (Grabner-Kra"uter et al., 2020).

\section{LITERATURE REVIEW}

Early study of the performance and difficulties of small businesses was completed by the Wiltshire Committee in 1971 in Australia. It defined a small business as one in which one or two persons are required to make all the critical management decisions: finance; accounting; personal; purchasing processing or servicing; marketing; selling without the aid of internal specialists; and with specific knowledge in only one or two functional areas (Subramaniam and Moslehi 2013). In Thailand Chittithaworn (2011) established that an enterprise is defined as an SME based on the value of assets or number of full-time employees. However, a more accepted and utilized quantitative definition of the Australian Bureau of Statistics (ABS, 2002) is that small businesses are companies with less than 20 employees and medium businesses are companies with less than 200 employees (Kuruppu, Mukheibir and Murta 2014).

Cheng, Ioannou and Serafeim's (2014) literature defined CSR as a concept whereby companies integrate social and environmental concerns into their stakeholder business operations and in their interaction with their stakeholders voluntarily. Generally, according to the Stakeholder Theory, it is all about open and transparent business practices based on ethical values and respect for stakeholders and the environment, which will contribute to the sustainable growth 
of an SME business (Tennyson, Serafin and Venables, 2003). Farina and Chambel (2014) state there is no justice in the above statements as they view CSR as operating a business in a manner that meets or exceeds the ethical, legal, commercial and public expectations that society has of business.

Chandler and Werther Jr (2013) authoritatively contend that trivial differences are germinating from researchers and authors about CSR, whereby definitions are driven from the way authors contextualize CSR. While in essence, CSR is an evolving concept that currently has various acceptable definitions. Turyakira, Venter and Smith (2014) added that the multiple definitions are in part, evidence of rather complex and multi-dimensional nature of CSR, worse enough its implementation and practices in different countries. A single term CSR has also been referred to under several different phrases (connotations), namely corporate citizenship, corporate philanthropy, corporate giving, corporate community involvement, community relations, community affairs, community development, corporate responsibility, global citizenship and corporate societal marketing. Some define corporate social responsibility from the economic point of view of the business, while some adopt from the environmental, ethics, legal, and some from the humanitarian or philanthropy mindset (Turyakira, Venter and Smith, 2014).

Conclusively, from all these different perspectives, there is a need for a common ground that CSR is about doing business sustainably and ethically, as well as treating or addressing Stakeholder concerns responsibly. Therefore, for this research, CSR is the commitment of a business entity to its employees, community, and environment to maintain sustainable living standards. This definition embraces all the elements that are generally included in CSR, such as the community, the environment, human rights, and the treatment of employees. Whereas some of these elements relate to social dimensions, others focus on stakeholders (e.g., community involvement, treatment of employees and their families). As such, this definition is consistent with development and Benn, Dunphy and Griffiths' (2014) multidimensional notion of CSR incorporating the work of Revathy (2012), who reviewed various definitions of CSR and found that the Stakeholder and the social dimensions receive the same attention based on frequency counts in research studies.

\section{METHODOLOGY AND PROCEDURES}

\section{Sample and Procedure}

The main purpose of this study is to analyze the perception of SMEs employees concerning CSR environmental practices. To achieve the study objective, data were collected from SMEs at Coimbatore City, in Tamil Nadu, India. As an emerging economy, around 71 percent of the small and medium-sized enterprises (SMEs) in India are more optimistic about domestic economic growth over the next 12 months compared to their Asian counterparts, a survey says. According to the survey commissioned by American Express and carried out by Oxford Economics, Indian SMEs are confident about their business performance in 2017 and 76 percent of those surveyed expect revenue growth of at least four percent during the year.

\section{Target Population}

Furthermore, the researchers employed a multiple-source, multiple informant design to create the respondent list. Many researchers employ a single-informant approach because as it is convenient and cost-effective, but this research has adopted multiple-informant approach 
which can provide data of far superior quality (Van Bruggen, Lilirn and Kracker, 2002). The data was selected from the employee lists provided by the personnel department of each firm, few employees as potential respondents, including a senior personnel manager, a marketing manager, a senior personnel manager, randomly selected middle managers, and frontline workers.

\section{Sample Design}

The sample was obtained through Multistage Stratified Random Sampling Procedure. To cover the diversity of economic development, the researcher has grouped the population of Small Medium Enterprises of Coimbatore City in Tamil Nadu, South India.

\section{Sampling Frame}

The sampling frame is all the MSME that are registered in the Udhyog Aadhar Memorandum in the Coimbatore City as of Feb 2018 Registered under SME Data of Coimbatore District Industries Association with a combination of MSME and UAM. The researcher selected three strata's among the total of 5533 from Micro/Mini Enterprises 681, Small Enterprises 4001, and Medium Enterprises 851. The study adopted multistage random sampling. The researcher approached 61 firms to study the employees' perceptions of CSR and environmental impact on CSR. Thus, the sample frame consisted of 9027 employees from the selected 61 firms. For determining sample size from a given population according to Krejcie R and Morgan D (1970), and based on the sample frame $(\mathrm{N})$ of 9027,369 employees were drawn as a sample for the study. The study hypothesis is tested with a cross-sectional field study of environment CSR practices among SMEs employees of Coimbatore district, the western part of Tamil Nadu, South India.

\section{Measures}

The items for all scales in the study were averaged to form the measures such that larger numbers signified higher levels of the variables towards Environment CSR practices and employee Organizational Identity. European Commission 2005 procedure was adopted along with Ashridge, 2005. These two references were used to develop the Environment CSR practices Scale. The researcher conducted interviews to identify context to describe the nature of CSR practices with environments. This process generated five items scale for environment CSR practices. The researcher generated the perceptions into CSR practices scales and administered them to employees, who responded using a 5-point Likert-type scale ranging from 1 (Strongly disagree) to 5 (strongly agree).

\section{Control variables}

The research also controlled the employee age, gender, and tenure for the analysis. Age and gender were controlled because both factors have been shown a good association with CSR perceptions. To measure the perceived level of SMEs employees and their CSR practices, a five-item Likert scale (where 1 is attributed to strongly disagree and 5 is attributed to strongly agree). 
Specifically, the following research steps were designed, corresponding to the various stages of our research. In the process of determining the SME employees' perception regarding the importance given to CSR environmental practices in considering their future practices identified as being the most important one for each environmental dimension (according to the calculated means, presented in a synthesis table).

The data was collected by a questionnaire circulated among SME employees in the Coimbatore City of Tamil Nadu. The sample collection was focused only on the employees who have an understanding of CSR and its policies. The chosen organizations were segregated based on their focus on CSR activities. The Friedman test was used to test that each of the practices identified as being the most important for each environmental dimension (according to the calculated means, presented in a descriptive analysis table) was the most important one. The results of this test can demonstrate if there are generally statistically significant variations between SME's employee opinions of these perception levels, and the Chi-Square estimated value gives Friedman's test. It indicates the asymptotic level of significance to compare the importance associated with the CSR practices with the highest means for each dimension to identify whether or not the CSR environmental practice with the highest mean is statistically more important than the rest of the practices included in that dimension. Reliability analysis for our measuring scales (questionnaire items) was conducted to test the reliability of our questionnaire the Alpha Cronbach indicator was used. The potential of the factor analysis and it is appropriateness is valid so the researcher conducted a confirmatory factor analysis also; as the initial step and we used the Kaiser-Meyer-Olkin (KMO) indicator (which measures the intensity of existing correlations between construct items) and Bartlett's test of sphericity to assess the potential for factor analysis (that indicates to us the existence or the non-existence of significant correlations between the items of a construct). Second, for each determined environmental dimension, confirmatory factor analysis was performed (limited the number of components to one) using SEM AMOS version 23. Finally, the entire "Environment CSR Construct" using the principal component analysis method because the entire variance of the variable was decomposed. Using the Confirmatory Factor Analysis, factor loadings were calculated for each of the defined environmental dimensions and each item included in these dimensions.

\section{Descriptive Statistics of the Respondents}

\section{Table 1 Respondents Demographic Profile}

The following Table 1 states the Descriptive statistics that was adopted to find out the mean, standard deviation, correlations and reliability of the study variables.

\begin{tabular}{cccccccc}
\hline Particulars & Classification & Frequency & Percent & Mean & S.D & Skewness & Kurtosis \\
\hline \multirow{3}{*}{ Age of the } & 20 to 30 Years & 34 & 9.2 & & & & \\
Respondents & 31 to 40 Years & 151 & 40.9 & & 0.7 & 0.39 & -1.3 \\
& 41 to 50 Years & 145 & 39.3 & & 5 & & \\
& Above 51 Years & 39 & 10.6 & & & & \\
\multirow{2}{*}{ Gender } & Male & 290 & 78.6 & & & & \\
& Female & 72 & 19.5 & 2.3 & 0.77 & 0.78 & -1.4 \\
\hline
\end{tabular}




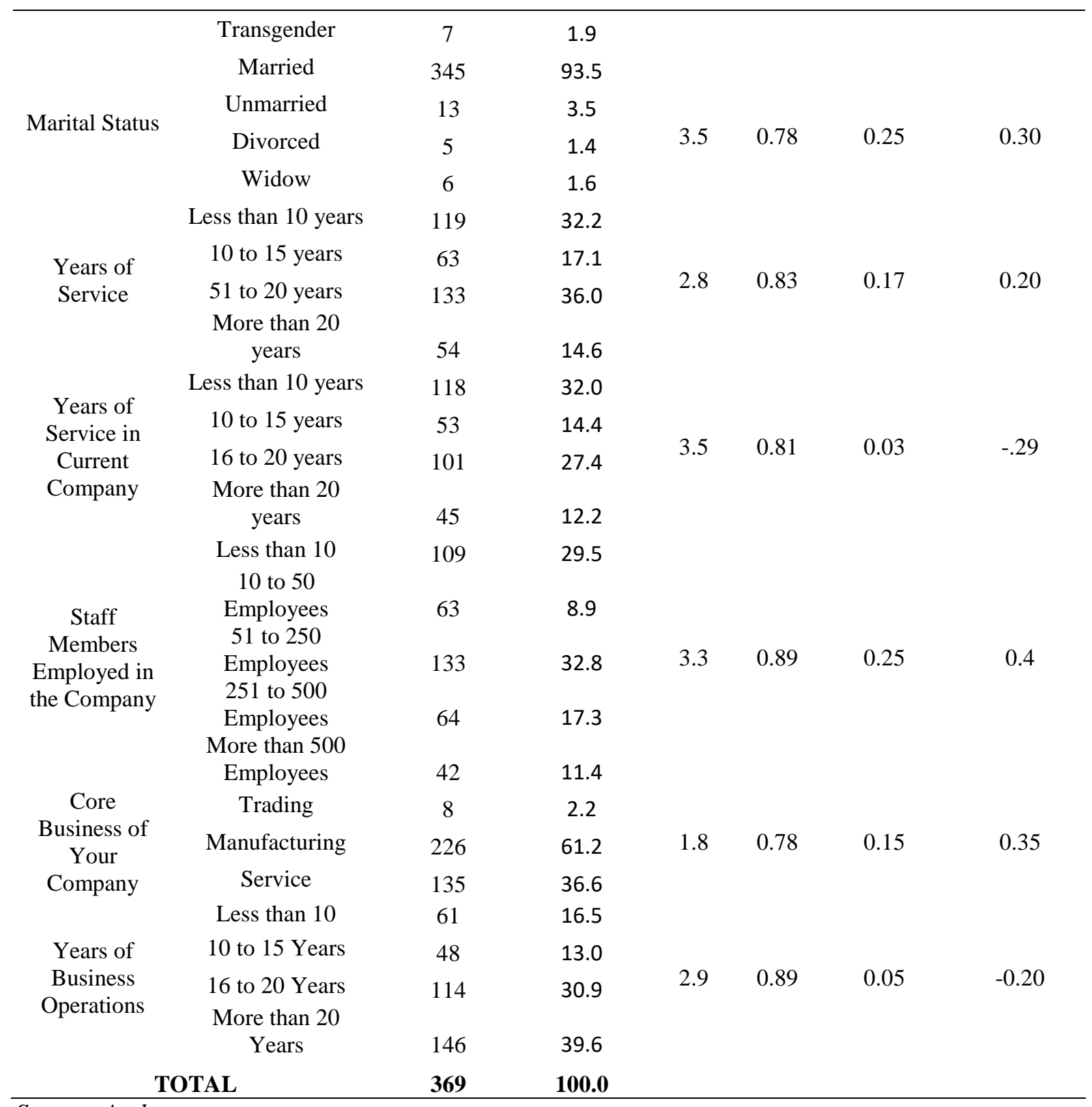

Source: Authors

Upon investigation, the respondent's age profile was found to be, $9.2 \%$ belong to less than 30 years of age, $41 \%$ are less than 40 years age category. $39 \%$ of the respondents were found to be less than 50 years and $11 \%$ of respondents were above 50 years. The mean of age is 2.5 and the standard deviation was 0.75 . The data for age profile was normal for skewness .39 and kurtosis as -1.3 respectively.

On the gender profile, it is found that 290 employees were male (78.6 percent) and 72 were female (19.5 percent) and 7 respondents were transgender ( 1.9 percent). The standard deviation was 0.77 and the data was normal as skewness and kurtosis were 0.78 and -1.39 respectively. From the respondents' marital status, it was found that $94 \%$ of the respondents were married and $4 \%$ were unmarried. The data was found to the normal.

As given in the total the largest sample represents the firm with 51-250 employees which indicate $33 \%$ of the sample. There are good numbers of firms with, many studies classify that the firm which has been less than fifty employees are called as micro firms. Definitely when counting the two groups: $38 \%$ of the sample represents the segment of employee size less than 
50. Finally, the employees which represent the segment of more than 250 employees are $29 \%$ thus; the sample is evenly established for further analysis concerning firm size.

From the above table 1, descriptive sampling analysis it is inferred that 61.2 percent of the company core business was manufacturing concern in Coimbatore district and 37 percent core business was service. Trading companies taken for the study are very less as 2.2 percent only. It is evident that from the above table 4.1 the category infers $40 \%$ of the firm business operates for more than 20 years. Then similar to that $31 \%$ of firm operates of more than 15 to 20 years. The remaining $13 \%$ of lies within 10 to 15 years of business operations and $17 \%$ of the firm falls under the year of business operations less than 10 years. It discusses the research that in Coimbatore district they are good quantum of companies well established and explains the continuous operations of the business. This proves the operating efficiency of the company.

Thus finding out the interest towards the CSR activities and their involvement really would justify the objectives required. Concerning the demographic features, the threshold value for Skewness should be nearer to zero and kurtosis should be within -3 to 3. According to Kolmogorov - Smirnov Test is been conducted by the researcher to prove the sample with a reference population with the probabilistic distribution.

Table 2: Means, Standard Deviations, Correlations, and Reliability estimates for Study

\begin{tabular}{lllllll}
\multicolumn{7}{c}{ Variables } \\
\hline Variable & Standard & Cronbach & & & \\
\hline Age & Deviation & Alpha & 1 & 2 & 3 & 4 \\
Gender & 0.75 & .65 & 1.00 & & & \\
Experience & 0.77 & .55 & 0.55 & 1.00 & & \\
Env.CSR Practices & 0.83 & .67 & 0.64 & $0.64^{*}$ & 1.00 & \\
\hline$\quad$ Note: $N=369, * p<0.05, * * p<0.01$ & .79 & $0.57^{*}$ & $0.53^{* *}$ & $.68^{* *}$ & 1.00 \\
$\quad$ Source: Authors & & & & & & \\
& & & & & &
\end{tabular}

From table 2, the relationship between the study variables reports a positive correlation and the reliability scores ranges from 0.55 to 0.68 , which reports a healthy sign of the chosen variables and gives a clear picture of the relevance of the items to be measured in the environmental dimension with the control variable.

Table 3: Reliability analysis for Environmental Dimensions

\begin{tabular}{llll}
\hline Construct & Environment Dimensions & $\boldsymbol{\alpha}$ Cronbach & \\
\hline & Waste Reduction & Initial & Final \\
& Recycling & 0.70 & 0.75 \\
& Energy Conservation & 0.55 & - \\
& Reduction of Water Consumption & 0.75 & 0.81 \\
Environment & Reduction of Air Pollutant & 0.78 & 0.85 \\
$($ Cronbach & Reduction in Packaging & 0.57 & - \\
alpha=0.89) & Sustainable Transportation & 0.64 & - \\
& Considers Environmental Impact when developing & 0.77 & 0.85 \\
& New Products such as energy usage, recyclability, & & \\
& pollution etc., & 0.61 & - \\
& Considers Environmental Friendly products and we & & \\
& are totally adopt Go Green concept & 0.75 & 0.81 \\
\hline
\end{tabular}

Source: Authors 
To test the consistency of the measuring scale used, we have used the Alpha Cronbach coefficient, results being presented in Table 3. From the table it is inferred the values obtained for the reliability analysis, the measuring scales can be defined which are reliable, having a value above the acceptable limit of 0.7 . After eliminating the less coefficient value in the dimension list, the items are refined and the measuring instrument is strengthened.

Table 2: Means, Standard Deviations and Confirmatory Factor Analysis

\begin{tabular}{|c|c|c|c|c|c|c|}
\hline \multirow{2}{*}{ Environment Dimension } & \multirow{2}{*}{ DM } & \multirow{2}{*}{ IM } & \multirow{2}{*}{ SD } & \multicolumn{3}{|c|}{ Confirmatory Factor Analysis } \\
\hline & & & & KMO & BTSL & $\mathrm{FL}$ \\
\hline Waste Reduction & & 4.21 & 0.891 & & & 0.85 \\
\hline Recycling & & 4.03 & 1.342 & & & 0.55 \\
\hline Energy Conservation & & 3.5 & 1.071 & & & 0.88 \\
\hline Reduction of Water Consumption & & 3.72 & 1.045 & & & 0.85 \\
\hline Reduction of Air Pollutant & & 4.10 & 1.093 & & & 0.45 \\
\hline Reduction in Packaging & & 3.55 & 1.076 & & & 0.57 \\
\hline Sustainable Transportation & 4.5 & 3.67 & 0.981 & 0.79 & $\mathbf{0 . 0}$ & 0.88 \\
\hline $\begin{array}{l}\text { Considers Environmental Impact when } \\
\text { developing New Products such as energy } \\
\text { usage, recyclability, pollution etc., }\end{array}$ & & 3.23 & 0.872 & & & 0.45 \\
\hline $\begin{array}{l}\text { Considers Environmental Friendly } \\
\text { products and we are totally adopt Go } \\
\text { Green concept }\end{array}$ & & 3.42 & 1.087 & & & 0.77 \\
\hline
\end{tabular}

Note: DM - Dimension mean; IM - Item Mean; SD - Standard Deviation; KMO - Kaiser-Meyer-Olkin indicator; BTSL - Bartlett test significance level; FL - Factor Loadings.

Source: Authors

Table 2 reports the adjusted measuring items to increase the calculated Alpha Cronbach value and thus assuring higher reliability of the research instrument. The research instrument used was categorized into two parts: one part was to focus on CSR environmental practices and the second part was on the profile of the respondents. For analyzing the CSR environmental practices, 9 items (water reduction, recycling, energy conservation, water consumption, air pollutant, packaging, sustainable transportation, considering environmental impact in developing new products and considers environmental friendly products to adopt green concept).

\section{Environmental Dimension CSR Practices}

Table 3: SME’s Measurement Model CSR Activities towards Environment Dimension

\begin{tabular}{lcccc} 
Environment Dimension & $\begin{array}{l}\text { Standardized } \\
\text { Loadings }\end{array}$ & $\begin{array}{l}\text { Error } \\
\text { Variance }\end{array}$ & t-value & $\mathbf{R}^{\mathbf{2}}$ \\
\hline Waste Reduction & 0.85 & 0.60 & 12.71 & 0.65 \\
Recycling & 0.55 & 0.55 & 13.565 & 0.72 \\
Energy Conservation & 0.88 & 0.48 & 13.565 & 0.71 \\
Reduction of Water Consumption & 0.85 & 0.54 & 13.211 & 0.65 \\
$\begin{array}{l}\text { Reduction of Air Pollutant } \\
\text { Reduction in Packaging }\end{array}$ & 0.45 & 0.33 & 13.565 & 0.68 \\
$\begin{array}{l}\text { Sustainable Transportation } \\
\begin{array}{l}\text { Considers Environmental Impact } \\
\text { when developing New Products }\end{array}\end{array}$ & 0.57 & 0.46 & 13.565 & 0.71 \\
$\begin{array}{l}\text { such as energy usage, recyclability, } \\
\text { pollution etc., }\end{array}$ & 0.45 & 0.45 & 13.565 & 0.54 \\
$\begin{array}{l}\text { Considers Environmental Friendly } \\
\text { products and we are totally adopt }\end{array}$ & & & & \\
Go Green concept & 0.77 & 0.43 & 13.199 & 0.68 \\
\hline
\end{tabular}


Model fit: Chi square $=418(d f=115)$ RMSEA $=0.06, N F I=0.85$, SRMR $=0.07$ and $G F I=$ 0.90

Source: Authors

From table 3 , it is inferred that "to what degree does your company participate in waste reduction" reports 0.85 and too how much is extremely related (.83) to your company and the findings explore same measurement with the study reported by Field's (2000) suggestions. In exploration to that it is how much your company engaged in Packaging Reduction corresponds to 0.57 . The items to how much your company is engaged with Energy Conservation reports (.88) as does "The environmental effect of your organization when new products are being developed" (.45). The other factors also report a good quantum of value-added to the dimension of research. The adjusted environmental performance measure as shown in the Table is the filtered new dimensions applicable for the current research.

Table 4: Adjusted Measurement Model of CSR Activities towards Environment Dimension

\begin{tabular}{|c|c|c|c|c|}
\hline Environment Dimension & $\begin{array}{l}\text { Standardized } \\
\text { Loadings }\end{array}$ & $\begin{array}{l}\text { Error } \\
\text { Variance }\end{array}$ & t-value & $\mathbf{R}^{2}$ \\
\hline Waste Reduction & 0.92 & 0.67 & 9.2 & 0.58 \\
\hline Energy Conservation & 0.91 & 0.51 & 9.7 & 0.55 \\
\hline Reduction of Water Consumption & 0.90 & 0.57 & 9.8 & 0.53 \\
\hline Sustainable Transportation & 0.95 & 0.51 & 8.8 & 0.51 \\
\hline $\begin{array}{l}\text { Considers Environmental Friendly products and we } \\
\text { totally adopt Go Green concept }\end{array}$ & 0.80 & 0.47 & 11.2 & 0.49 \\
\hline
\end{tabular}

Source: Authors

Table 4 shows that waste reduction and water consumption reduction are the most frequent environmental activities, with above 90 percent showing that their companies are very or fairly extensively engaged in energy conservation. Similarly, $80 \%$ of the respondents say that their companies are largely or fairly engaged in environment-friendly products and the go green concept. Energy conservation seems to be one of the prevalent environmental activities, with $91 \%$ of participants saying that their company is largely or very extensively engaged in this activity. The concept of Go green is also well familiar among the respondents of the research which reports $80 \%$. Hence, the researcher proves that the environmental dimension is very high among SME employees.

Table 5: Chi-Square Analysis of CSR Activities towards Environment Dimension

\begin{tabular}{llll}
\hline Environment Dimension & $\begin{array}{l}\text { Chi-Square } \\
\text { Value }\end{array}$ & df & $\begin{array}{l}\text { Asymptotic } \\
\text { sig ( 2 sided) }\end{array}$ \\
\hline Waste Reduction & 10.27 & 2 & 0.08 \\
Recycling & 13.12 & 2 & 0.02 \\
Energy Conservation & 10.87 & 2 & 0.06 \\
Reduction of Water Consumption & 12.27 & 4 & 0.05 \\
Reduction of Air Pollutant & 15.56 & 6 & 0.04 \\
Reduction in Packaging & 11.92 & 4 & 0.04 \\
Sustainable Transportation & 11.10 & 2 & 0.04 \\
Considers Environmental Impact when developing New Products & 11.60 & 2 & 0.04 \\
such as energy usage, recyclability, pollution etc., & & \\
Considers Environmental Friendly products and we are totally adopt & 10.74 & 2 & 0.01 \\
Go Green concept & & 2 \\
\hline
\end{tabular}

Source: Authors 
From table 5, it is inferred that the asymptotic value of the environmental corporate social responsibilities activities is within the desired limit of expected value, thus these measuring variables contribute the maximum for the environmental construct and the significance is also proved.

\section{DISCUSSION}

CSR methods in organizations have focused on the triggers and impacts of CSR in organizations today, with less regard to CSR procedures in clients ' organizations (for example, between executives and coworkers). As more organizations work, beneficial relationships between staff and clients are essential for organizational accomplishment based on environment service. Staff with unsatisfied environment-related procedures can lead to client sales and reduce an enterprise's effectiveness. Environment CSR procedures can simultaneously reduce employee satisfaction and perception.

Since CSR is consumer-friendly for environments, this research is of three-fold theoretical significance. First, we found that perception is connected with employer client CSR operations, i.e. the ethical perception of staff to clients by experiencing client CSR and reciprocating with client CSR procedures. Our results are consistent with judicial reciprocity processes, suggesting that individuals can react by engaging in counterproductive work activity directed at their sources in cases of negative relationships.

These findings are consistent with a spiral in inner CSR studies of CSR processes. External CSR and the Prestige are perceived as mediators of environment CSR procedures and employee CSR procedures. The connection between CSR and Org Environments, Identity shall be influenced by its own internal apparent CSR. The above-mentioned effects are of linear complexity, as one feasible reason for these insignificant outcomes. That means, employees with CSR client activities can be encouraged to target environments with CSR practices when perceived external CSR reaches specific levels; however, these effects cannot happen in less concentrated areas of welfare benefits. One of the outcomes is that the perceived external CSR does not offset the environment-employee identification connection alone unless it leads to perceived external prestige. As far as the function of PEP is concerned, the results indicate that Perceived External Prestige mediates the link between CSR practice and employee identity. This finding indicates that relationships with clients can enhance the apparent internal status of staff and thus reduce their environment-friendliness. Third, data show that the presumed internal CSR and internal status were internal. We extend this study by demonstrating that perceived external prestige is associated with a rise in employee organizational identity towards environments, and the research considers the role of perceived external CSR in this connection. The primary interpretation of this study is that the perceived external CSR methods improve efficiency and the prestigious external standards of the worker. One outcome of the increased stress in Perceived External Prestige is that it subsequently reduces the capacity of staff to provide environment service and increases workers ' client service.

\section{CONCLUSION AND SUGGESTION}

Although every business is intended to create positive financial outcomes and multiply values to assure profitability, excessive or reckless exploitation of natural resources cannot be morally justified in the long term. A focus on short-term earnings cannot jeopardize future generations' 
well-being. As a result, when examining the management of socially responsible actions of companies, or corporate social responsibility (CSR), the link between the CSR concept and sustainable development cannot be overlooked. They both pertain to the same areas of enterprise effect and allow for the achievement of far-reaching social, ecological, and economic goals based on ethical principles. Humanity is currently caught in a double race. On the one hand, we feel obligated to accelerate scientific progress and economic prosperity; on the other hand, we must keep at least one step ahead of the ecological calamity. In this crowded world, we require new principles to guide our lives. In response to these requirements, the ideas of sustainable development and corporate social responsibility, or CSR, emerged. Entrepreneurs' interest in corporate social responsibility toward a wide range of stakeholders is rising.

Even though many argue that CSR should not be focused on charity, marketing, or public relations and that the inclusion of CSR into management programs was merely an ad hoc response to the needs of society following the global financial crisis of 2008, with no significant change in management programs, many argue that CSR should be focused on charity, marketing, and public relations. Businesses should respond appropriately in the new era of business administrators, designing, planning, and executing CSR solutions in all domains of company administration, not simply in accordance with general standards of business ethics and CSR principles. Although environmental management techniques do not necessarily improve organizational client satisfaction, numerous studies show that taking a position on social problems may contribute to long-term competitive advantage. Our research has found that businesses in the Coimbatore region take social responsibility very seriously, make efforts to reduce their negative impact on the environment and the health of their employees, and management has a high level of ecological awareness and sees social responsibility as an investment that can lead to a competitive advantage in the long run.

According to our findings, companies most frequently engage in environmental protection efforts focused at reducing waste and emissions to water and soil, particularly through new technologies and investments in pro-environmental infrastructure. This means that businesses must assess their impacts on various resources responsibly and explore ways to reduce the environmental responsibilities of their operations. Although our research findings are confined to the perspective of companies operating in one location, it should be noted that this is one of Tamil Nadu's industrial regions with comparatively low levels of hazardous emissions when compared to the other regions. As a result, we sought to learn about the reasons and perspectives that motivate employees to adopt environmentally friendly behaviors in order to prevent the destruction of the environment as a whole or its components. This is critical for implementing CSR principles and, more broadly, for achieving sustainable development.

\section{CONFLICT OF INTERESTS}

The authors declare no conflict of interest.

\section{FUNDING}

For this research work, the authors did not receive funds from any organization. 


\section{REFERENCES}

Agudelo, M. A. L., Jóhannsdóttir, L., \& Davídsdóttir, B. (2019). A literature review of the history and evolution of corporate social responsibility. International Journal of Corporate Social Responsibility, 4(1), 1-23. https://doi.org/10.1186/s40991-018-0039-y

Ashforth B. and Mael F. (1996) Organizational Identity and Strategy as a Context for the Individual. Advances in Strategic Management 13, 17-62. https://www.jstor.org/stable/40397751

Ashforth, B. E., Harrison, S. H., \& Corley, K. G. (2008). Identification in Organizations: An Examination of Four Fundamental Questions. Journal of Management,34(3), 325-374. https://doi.org/10.1177/0149206308316059

Ashmore, R. D., Deaux, K., \& McLaughlin-Volpe, T. (2004). An Organizing Framework for Collective Identity: Articulation and Significance of Multidimensionality. Psychological Bulletin, 130(1), 80-114. https://doi.org/10.1037/0033-2909.130.1.80

Argandoña, A., \& von Weltzien Hoivik, H. (2009). Corporate social responsibility: One size does not fit all. Collecting evidence from Europe. Journal of Business Ethics, 89(3), 221-234. https://doi.org/10.1007/s10551-010-0394-4

Bandura, A. (1971), Social Learning Theory, General Learning Press, New York, NY.

Benn, S., Edwards, M., \& Williams, T. (2014). Organizational change for corporate sustainability. Routledge. https://doi.org/10.1108/00483480410518095

Castka, P., Balzarova, M. A., Bamber, C. J., \& Sharp, J. M. (2004). How can SMEs effectively implement the CSR agenda? A UK case study perspective. Corporate Social Responsibility and Environmental Management, 11(3), 140-149.https://doi.org/10.1002/csr.62

Camilleri, M. A. (2017). Corporate sustainability and responsibility: creating value for business, society and the environment. Asian Journal of Sustainability and Social Responsibility, 2(1), 59-74.AJSSR 2, 59-74 (2017). https://doi.org/10.1186/s41180-017-0016$\underline{5}$

Cheng, B., Ioannou, I., \& Serafeim, G. (2014). Corporate social responsibility and access to finance. Strategic Management Journal, 35(1), 1-23. https://doi.org/10.1002/smj.2014.35.issue-1

Chandler, D. B. and Werther Jr, W. B. (2013). Strategic Corporate Social Responsibility: Stakeholders, Globalization, and Sustainable Value Creation. Miam. Sage Publications.

Chittithaworn, C., Islam, M. A., Keawchana, T., \& Yusuf, D. H. M. (2011). Factors affecting business success of small \& medium enterprises (SMEs) in Thailand. Asian social science, 7(5), 180190. https://doi.org/10.5539/ass.v7n5p180

De Roeck, K., \& Delobbe, N. (2012). Do environmental CSR initiatives serve organizations' legitimacy in the oil industry? Exploring employees' reactions through organizational identification theory. Journal of Business Ethics, 110(4). https://doi.org/10.1007/s10551-012$\underline{1489-\mathrm{x}}$

Farina, A., \& Chambel, M. J. (2014). Business for Social Responsibility. Encyclopedia of Quality of Life and Well-Being Research, 45(3), 476-479.

Fenwick, T. (2010). Learning to practice social responsibility in small business: challenges and conflicts. Journal of Global Responsibility, 1 (1), 149-169.. https://doi.org/10.1108/20412561011039753

Friedman, A. L., \& Miles, S. (2001). SMEs and the environment: Two case studies. EcoManagement and Auditing: The Journal of Corporate Environmental Management, 8(4), 200209.https://doi.org/10.1002/ema.166

Friedman A., Miles S. and Adams C. (2000). Small and Medium-Sized Enterprises and the 
Environment: Evaluation of a Specific Initiative Aimed at all Small and Medium-Sized Enterprises. Journal of Small Business and Enterprise Development 7(4), 325-42. https://doi.org/10.1108/EUM0000000006849

Garetti, M., \& Taisch, M. (2012). Sustainable manufacturing: trends and research

challenges. Production planning \& control, 23(2-3), 83-104. https://doi.org/10.1080/09537287.2011.591619

Gharleghi, B., Jahanshahi, A.A. and Nawaser, K. (2018). The outcomes of corporate social responsibility to employees: empirical evidence from a developing country, Sustainability, 10 (3), 698-713. https://doi.org/10.3390/su10030698

Glavas, A. (2016). Corporate social responsibility and employee engagement: Enabling employees to employ more of their whole selves at work. Frontiers in psychology, 7, 796. https://doi.org/10.3389/fpsyg.2016.00796

Grabner-Kräuter, S., Breitenecker, R. J., \& Tafolli, F. (2021). Exploring the relationship between employees' CSR perceptions and intention to emigrate: Evidence from a developing country. Business Ethics, the Environment \& Responsibility, 30, 87-102. https://doi.org/10.1111/beer.12291

Ioannou, I., \& Serafeim, G. (2015). The impact of corporate social responsibility on investment recommendations: Analysts' perceptions and shifting institutional logics. Strategic Management Journal, 36(7), 1053-1081. https://doi.org/10.1002/smj.2268

Jenkins, H. (2006). Small business champions for corporate social responsibility. Journal of business ethics, 67(3), 241-256. https://doi.org/10.1007/s10551-006-9182-6

Kuruppu, N., Mukheibir, P., \& Murta, J. (2014). Ensuring small business continuity under a changing climate: The role of adaptive capacity. Applied studies in climate adaptation, 429. https://doi.org/10.1002/9781118845028.ch48

Mayes R, McDonald P, Pini B. 'Our' Community: Corporate Social Responsibility, Neoliberalisation, and Mining Industry Community Engagement in Rural Australia. Environment and Planning A: Economy and Space. 2014;46(2):398-413. https://doi.org/10.1068/a45676

O'Dwyer, B. (2003), The ponderous evolution of corporate environmental reporting in Ireland. Recent evidence from publicly listed companies. Corp. Soc. Responsib. Environ. Mgmt, 10: 91100. https://doi.org/10.1002/csr.33

Perez-Sanchez, D., Barton, J.R. and Bower, D. (2003), Implementing environmental management in SMEs. Corp. Soc. Responsib. Environ. Mgmt, 10: 6777. https://doi.org/10.1002/csr.37

Revathy, B. (2012). Corporate social responsibility: An implementation guide for business. Far East Journal of Psychology and Business, 6(2), 15-31.

Subramaniam, I. D., \& Moslehi, M. M. (2013). Does workforce innovation mediate the relationship between internal factors and performance in Malaysian entrepreneurial SMEs?. Asian Social Science, 9(9), 45. https://doi.org/10.5539/ass.v9n9p45

Tonin, Mirco and Vlassopoulos, Michael, (2013). Do Social Incentives Matter? Evidence from an Online Real Effort Experiment, Review of Environment, Energy and Economics - Re3, https://EconPapers.repec.org/RePEc:fem:femre3:2013.01-02

Turyakira, P., Venter, E., \& Smith, E. (2014). The impact of corporate social responsibility factors on the competitiveness of small and medium-sized enterprises. South African Journal of Economic and Management Sciences, 17(2), 157-172. https://doi.org/10.4102/sajems.v17i2.443

Vives A. (2006). Social and Environmental Responsibility in Small and Medium Enterprises in Latin America. Journal of Corporate Citizenship 21, 39-50

Verbeke, A., \& Tung, V. (2013). The Future of Stakeholder Management Theory: A Temporal 
Perspective. Journal of Business Ethics, 112(3), 529-543. http://www.jstor.org/stable/23327338

Whetten, D. A., \& Mackey, A. (2002). A Social Actor Conception of Organizational Identity and Its Implications for the Study of Organizational Reputation. Business \& Society, 41(4), 393-414. https://doi.org/10.1177/0007650302238775

Żelazna, A., Bojar, M., \& Bojar, E. (2020). Corporate Social Responsibility towards the Environment in Lublin Region, Poland: A comparative study of 2009 and 2019. Sustainability, 12(11), 4463. https://doi.org/10.3390/su12114463 